\title{
Letters
}

All letters are subject to editing and may be shortened. General letters can be sent to bjgpdisc(arcgp.org.uk (please include your postal address for publication), and letters responding directly to BJGParticles can be submitted online via eLetters. We regret we cannot notify authors regarding publication.

For submission instructions visit: bjgp.org/letters

\section{GP recruitment and retention}

As a GP registrar, I was rather downhearted after reading the letter by $\mathrm{Dr}$ Glasspool in the March BJGP. Is it that bad? Are we really in crisis? Are all the GPs retiring, locuming, and emigrating? Dr Glasspool helpfully points us to social media for a true picture, and it seems he is right! A search on Twitter for 'GP recruitment', 'GP workload', and 'GP crisis' finds 42 negative tweets just in the last 7 days, most, seemingly from doctors. We are crumbling under the pressure', '74\% unmanageable workload', and 'We need to have a ceiling on our workload - a GP colleague had 105 phone calls and 15 patients to see while on call - that's unsafe', were just some of the things freely available to find on Twitter. A search on The Huffington Post finds two demoralising articles., ${ }^{2,3}$ Should I change career? Is there any hope?

Then, just yesterday, I attended the Royal College of General Practitioners' (RCGP) GP recruitment event in Hull. I was asked to go, to answer any questions the delegates had about the GP training scheme. I sat down and listened to the speakers, four GPs from the Yorkshire area. I was struck by the vigour, energy, and enthusiasm they had for their work; they clearly loved general practice, and spoke with passion about all aspects of being a GP. Even when asked by one of the delegates about the worst part of their job, there was no hint of burnout or unmanageable workloads or stress in their answers. Any doubts I had over my chosen career had vanished by the end of the evening.

I am aware that these RCGP events are exactly what 'saddens' Dr Glasspool who argues that the College is wrongly encouraging students into a speciality which is currently broken', but the four speakers were not politicians using 'spin' to put on a brave face before an election; they were honest, hard-working doctors who simply shared their passion for general practice.

Daniel Jones,

GPST3, Hull York Medical School, York. E-mail: ugm4djjdagmail.com

\section{REFERENCES}

1. Glasspool J. GP recruitment and retention. Br J Gen Pract 2015; DOI: 10.3399/bjgp15X683881.

2. Norris Z. The day I failed as a GP. Huffington Post 2015; 1 Feb: http://www.huffingtonpost.co.uk/ dr-zoe-norris/nhs-stress b 6586300.html laccessed 7 Apr 2015).

3. Norris Z. The NHS frontline - the reality of being a doctor in today's NHS. Huffington Post 2014; 7 Dec: http://www.huffingtonpost.co.uk/dr-zoe-norris/nhsfrontline-the-reality b 6279784. html laccessed 7 Apr 2015).

DOI: 10.3399/bjgp15X684721

\section{The CQC inspections: not 'outstanding', may be 'good', but 'requires improvement'}

I am an enthusiast for quality improvement and have led my practice in external validation of our quality for 30 years. Among other quality tests this includes completing the Royal College of General Practitioners Quality Practice Award (QPA) three times. The QPA was difficult but fair. All the criteria and standards were explicit and took about a year to complete and document in advance of a full day inspection of the practice by a team of thoughtful QPA inspectors.

In contrast, I am dismayed by the mission creep of the Care Quality Commission (CQC) inspections, ${ }^{1}$ some of its faux quality and its ratings approach to improvement at a time when general practice is struggling on so many fronts (such as, workload, recruitment, and morale). I worry that $\mathrm{CQC}$ is currently causing more problems than it is solving (such as, workload, recruitment, and morale) which, in turn, may worsen quality. There are many ways that quality can be assessed and although it's reasonable to expect that a practice is safe, effective, caring, responsive to peoples needs, and well led; you also need explicit criteria that are good ways of assessing these CQC five key questions, and you need sensible standards of achievement for each criteria. It is then reasonable to publish a practice's achievement against each criteria and standard. We should never be surprised that $50 \%$ of practices are rated below average for one or more criteria, or that $25 \%$ of practices are in the lowest quartile. At the time of writing my practice has not been inspected but we know that next week we might be told we have 2 weeks to prepare for the inspection. The CQC may consider itself a powerful agent for change but in our preparations for a CQC inspection I haven't found the CQC helpful in responding to my enquiries about what they think is good practice. There must be a better way, and in the meantime. I question whether the CQC itself is really safe, effective, caring, and responsive to people's needs, and well led.

Terry Kemple,

GP, Horfield Health Centre, Bristol.

E-mail: tkaelpmek.demon.co.uk

\section{REFERENCE}

1. Blake A, Sparrow N, Field S. The CQC inspections: what they mean for general practice. Br J Gen Pract 2015; DOI: 10.3399/bjgp15X683845

DOI: 10.3399/bjgp15X684733

\section{CQC intelligent monitoring}

I would hope that Steve Field, maintaining the transparency to which he and the Care Quality Commission (CQC) aspire, will review the effect of publishing their 'intelligent monitoring' (IM) on the practice in which I was proud to be a partner for 29 years.

The announcement of the practice's IM putting it in the lowest banding (Band 1) came as a real shock to the doctors, nurses, and office staff and, most notably, a large number of the 29000 patients.

The 'outstanding' result of the ensuing CQC inspection made the IM seem exceedingly fallible in its apparent lack of both content, and face, validity.

Might the CQC's transparency now both 
allow it to publish any discussions about the utility of the words 'intelligent' and 'monitoring' in this context and make any apologies to those, for whom IM has proved both inaccurate and reputationally risky, highly visible?

\section{Guy Bradley-Smith,}

Freelance GP, NEW Devon CCG Clinical Commissioning Lead for Learning Disability, and Honorary Clinical Lecturer at Exeter University Medical School, Exeter. E-mail: guy.bradley-smithlanhs.net

\section{REFERENCE}

1. Blake A, Sparrow N, Field S. The CQC inspections: what they mean for general practice. Br J Gen Pract 2015; DOI: 10.3399/bjgp15X683845.

DOI: 10.3399/bjgp15X684745

\section{How the NCT will bring down the NHS}

Being a recent new mum I can see this argument from both perspectives, ${ }^{1}$ and I think it's unfair to blame organisations such as the National Childbirth Trust (NCT) for new mother neurosis. I was fortunate that I could attend my antenatal classes at my local GP practice, however, I did feel that all of the emphasis was placed on the 'birthplan' (which rarely happens) and how 'easy' breastfeeding is, and nothing was placed on how to spot when your baby is unwell. Now the NCT provide classes with information about the early days, weaning, and even first aid, and I have met many a mum who feels much more comfortable with their new role after attending these postnatal courses. I agree that sometimes people put too much emphasis on things that may be mentioned in classes or by the health visitor, such as what their newborn's poo looks like, but I can assure you that some NHS professionals don't help either: when I took my just-turned 9 month old to be weighed, I was quizzed about his bruises (Mongolian blue spots, mentioned in his red book) and why he wasn't walking yet, and to finish, I was told off for letting his weight go up one centile! Many of my new parent friends have little trust in health visitors and social workers, which is very sad as they are a great source of information and we really need to work at changing this. However, instead of slandering the organisations such as NCT when a mum presents with a healthy baby, perhaps we should take the opportunity to teach the parent about common childhood problems and not forget to ensure that there is no underlying postnatal anxiety or depression?

Sophie Emesih,

Foundation Doctor.

E-mail: sophie.emesihlanhs.net

\section{REFERENCE}

1. Staten A. How the NCT will bring down the NHS. $\mathrm{Br}$ J Gen Pract 2015; DOI: 10.3399/bjgp15X684481.

DOI: 10.3399/bjgp15X684757

\section{Always add indication labelling to all repeat prescriptions}

Multiple repeat prescriptions for patients is the default position in modern day primary care as described in Cahill's editorial." Adding indication labelling to the drug instructions firmly links the drug with its clinical indication (http://clinicalindications. $\mathrm{com} /$ ). For example, the drug allopurinol's usage instruction would be 'Take one daily to prevent gout'. Patients are delighted to have this simple way of knowing what each drug is used for and saves the prescriber from having to repeatedly explain each drug's use in the consultation. This process is recommended for use by all doctors in the General Medical Council guidelines in Good Practice in Prescribing, in 2013. ${ }^{2}$ Clinical indications works seamlessly with uploads to the NHS Spine. Sadly, no computerised version of this process is yet available for harried clinicians, but I remain convinced of its long-term merit. Remember it was over 50 years ago that we starting naming the drug rather than just stating "please take this prepared mixture', so isn't it high time for us to state the indication?

\section{Nigel James Masters,}

Retired GP and Records Compliance Officer, Highfield Surgery, Hazelmere. E-mail: nigel.mastersanhs.net

\section{REFERENCES}

1. Cahill P. Prescribing for patients with multimorbidity: aiming to tailor to patient-set goals. Br J Gen Pract 2015; DOI: 10.3399/ bjgp15X683857.

2. General Medical Council. Good practice in prescribing and managing medicines and devices. http://www.gmc-uk.org/Prescribing Guidance_2013_50955425.pdf laccessed 7 Apr 2015).

DOI: 10.3399/bjgp15X684769

\section{Childhood UTI}

The overall incidence of laboratory-proven urinary tract infection (UTI) (5.9\%) and presampling suspected UTI (>8\%) among 'acutely unwell children' both seem, from my primary care experience, unusually high. The study suggests we are 'missing' about half of UTIs at first presentation, and concludes that we are under-treating UTIs. My own impression from my general medical clinic in secondary care is that we are over-diagnosing UTI and often overtreating as a result: primarily because of the diagnosis of UTI based exclusively on irritative symptoms alone. I would be interested to know, by way of a control, what the incidence of laboratory-confirmed UTI would be; using identical sampling among a matched group of well children. I suspect that the diagnostic criteria in the National Institute for Health and Care Excellence clinical guidance are appropriately broad so as to avoid missing those occasional cases of genuine clinically-significant infection that occur in the absence of pyuria, but which same criteria are, for the purposes of a research project proposing to measure the actual incidence of clinically significant infection, somewhat over-inclusive.

Adrian Crofton,

GP and Associate Paediatrician, Carden Medical Centre, Aberdeen and Royal Aberdeen Children's Hospital, Aberdeen. E-mail: adrian.croftonanhs.net

\section{REFERENCE}

1. Butler CC, O'Brien K, Pickles T. Childhood urinary tract infection in primary care: a prospective observational study of prevalence, diagnosis, treatment, and recovery. Br J Gen Pract 2015; DOI: $0.3399 /$ bjgp 15X684361 